\title{
Nodal Burkitt'S Lymphoma in an AIDS Patient under HAART with a Good Clinical, Immunological and Virological Response
}

\author{
Cárdenas $\mathbf{G}^{1,2}$, Corti $\mathrm{M}^{1,2^{*}}$, Campitelli $\mathrm{A}^{3}$, Narbaitz $\mathrm{M}^{4}$, Bistman $\mathrm{A}^{5}$ \\ ${ }^{I}$ Division of HIV/AIDS, Infectious Diseases F. J. Muñiz Hospital, \\ ${ }^{2}$ Medicine Department, Infectious Diseases Orientation, University of Buenos Aires, School of Medicine, \\ Buenos Aires, Argentina. \\ ${ }^{3}$ Histopathology Laboratory, F. J. Muñiz Hospital, Buenos Aires, Argentina \\ ${ }^{4}$ National Academy of Medicine, Histopathology Laboratory, Buenos Aires, Argentina \\ ${ }^{5}$ Oncohaematological Section, Ramos Mejía Hospital, Buenos Aires, Argentina
}

*Corresponding Author: Marcelo Corti, Department of HIV/AIDS, Infectious Diseases F. J Muñiz Hospital, Puán 381, 2nd Floor, C 1406 CQG, Buenos Aires, Argentina.

\begin{abstract}
Non-Hodgkin lymphoma (NHL) of the B-cell type is a frequent complication in HIV-infected patients. The risk to develop NHL is 100 to 200 times higher compared with the general population. The influence of highly active antiretroviral therapy (HAART) on the incidence of some subtypes of AIDS-related lymphomas, including diffuse large B-cell lymphoma (DLBCL), Burkitt's lymphoma (BL) and plasmablastic lymphoma $(P B L)$ is uncertain and lower with respect to the effect on the develop of opportunistic infections. Generally, NHL is associated with the immunodeficiency related with the retrovirus, but these neoplasms can be seen in patients under HAART with a good clinical, immunological and virological condition. BL has frequently been reported as a neoplasm in HIV infected patients.

Here we present a patient infected with HIV who developed a nodal BL during HAART with immune reconstitution and undetectable viral load. Patient was treated with the same scheme of HAART plus chemotherapy with a prolonged survival and a complete remission of the lymphoproliferative disorder.
\end{abstract}

Keywords: Non-Hodgkin lymphoma, Burkitt's lymphoma, HAART, HIV

\section{INTRODUCTION}

Patients infected with human immunodeficiency virus (HIV) have a high risk to develop nonHodgkin (NHL) lymphomas. This risk is 100 to 300 times higher in comparisson with the general population [1]. Highly active antiretroviral therapy (HAART) reduce the incidence of some subtypes of NHL, especially, primary central nervous system lymphoma (PCNSL), but the influence on other subtypes of lymphoma, including diffuse large $\mathrm{B}$ cell lymphoma (DLBCL), Burkitt's lymphoma (BL), plasmablastic lymphoma (PBL) and Hodgkin's disease (HD) is uncertain.

Here, we describe an HIV-infected patient under HAART, with a good clinical, immunological and virological response, who developed a nodal
BL, successfully treated with chemotherapy plus HAART.

\section{CASE Report}

A 36 year-old man, with recent diagnosis of HIV infection started treatment on HAART with plasma viral load of 77900 copies $/ \mathrm{mL}$ and CD4-T cell count of 422 cell $/ \mu \mathrm{L}$ (16\%).

$\mathrm{He}$ was negative for syphilis, HCV, HBV, Toxoplasma gondii and Trypanosoma cruzi antibodies. Routine laboratory analysis was normal. In this setting, he started HAART based on tenofovir, emtricitabine, darunavir/ritonavir, QD, with a good adherence and tolerance. Two months later, he consulted due to the appearance of a large tumor lesion located in the right submaxillary region without other symptoms (figure 1). 


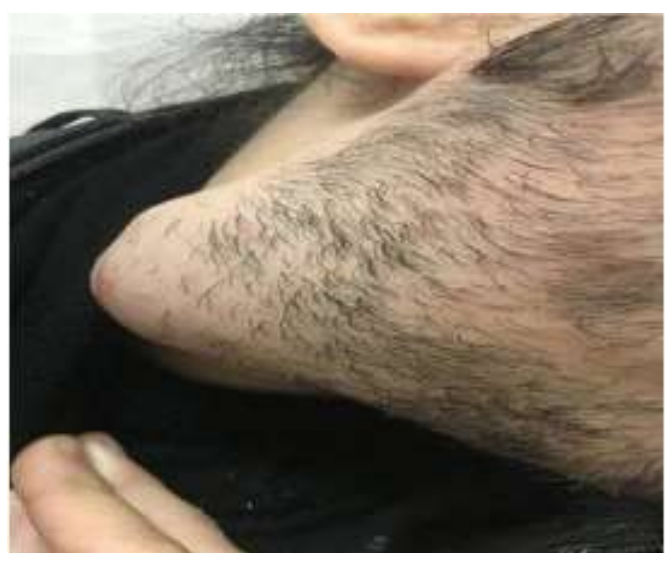

Figure 1

Systemic examination was normal; the blood tests revealed hemoglobin of $13 \mathrm{~g} / \mathrm{dL}$, WBC $8700 / \mathrm{mL}$ (43\% of neutrophils and $42 \%$ of lymphocytes) and 275000 platelets/mm3. Renal and liver functions were normal. Lactate deshidrogenase (LDH) was elevated $647 \mathrm{UI} / \mathrm{mL}$. The plasma viral load was undetectable $(<40$ copies/mL) and the CD4-T-cell count of 387 cell $/ \mu \mathrm{L}$. A computed tomography (CT) scan of the head and neck was made and showed a large, heterogeneous adenomegaly of 5,3 $\mathrm{mm}$ of transverse diameter located below the dental arch (figure 2).

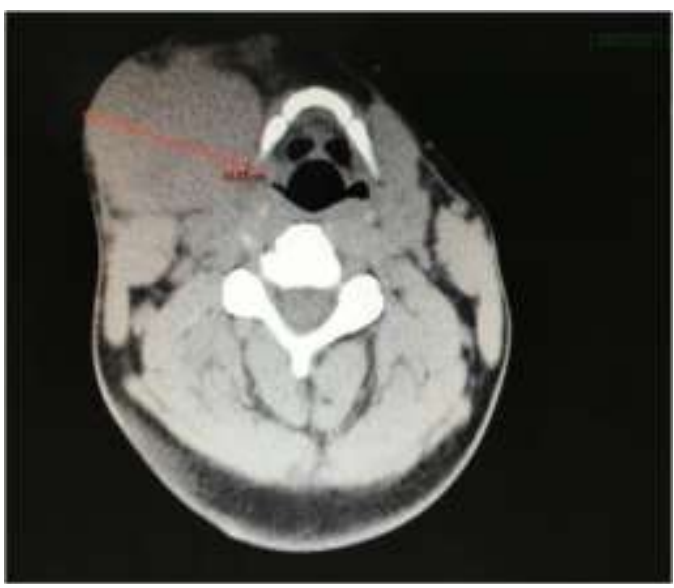

Figure 2

An excisional biopsy was done; histopathological examination of biopsy smears revealed a diffuse monotonous infiltrate of medium to large-sized monomorphic cells with round nuclei, multiple nucleoli and scarce basophilic cytoplasm. The nuclei are round with clumped chromatin and contain multiple basophilic nucleoli. Scattered macrophages, impart the image of "scarry sky pattern" (figure 3).

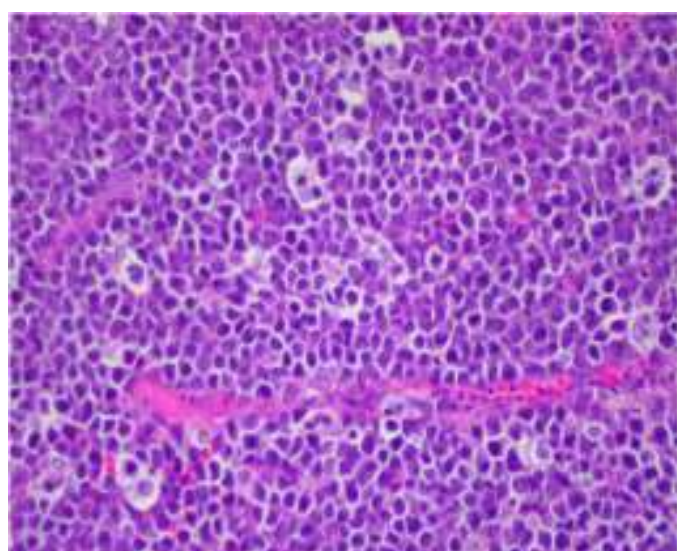

Figure 3

The atypical cells expressed CD20, CD10 and BCL6. Ki67 antigen was > 98\%. A CT scan of brain, thorax, abdomen and pelvis showed no evidence of neoplasm. The bone marrow biopsy was negative to atypical cell infiltration and a lumbar puncture was also negative for neoplastic cells. Final diagnosis was BL stage I. Patient was started on chemotherapy plus the same scheme of HAART. He received CODOX$\mathrm{M}$ (cyclophosphamide, doxorubicin, vincristine with intrathecal methotrexate and cytarabine followed by high-dose of systemic methotrexate) e IVAC (ifosfamide, cytarabine, etoposide and intrathecal methotrexate) which was associated with a good clinical, immunological and virological response (figure 4). Two years after diagnosis of BL he is in a good clinical condition.

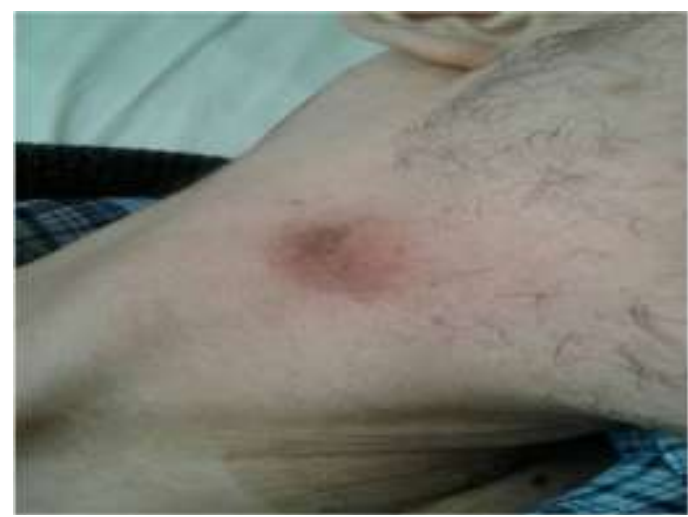

Figure 4

\section{DiscuSSION}

NHL is a heterogeneous group of malignancies that, in HIV seropositive patients, are of B phenotype and high grade. Also, generally, AIDS-associated NHL are diagnosed in advanced stages of the neoplasm diseases and with frequent extranodal locations as primary 
manifestation of the disease [2]. Actually, the best treatment of NHL in AIDS patients is based on the combination of HAART plus chemotherapy $[3,4]$.

In HIV/AIDS patients, BL account for about $35 \%$ to $40 \%$ of all NHL in comparison with $1 \%$ to $2 \%$ in the general population. The HIV infection is an infection that should be ruled out in cases of BL [5]. BL is an aggressive B-cell lymphoma with three clinical forms: endemic BL, usually associated with Epstein-Barr virus (EBV) in his pathogenesis; sporadic variant, less related to EBV infection and immunodeficiency or immunosuppression associated BL, that is seen especially in HIV-seropositive patients [6]. BL in HIV patients is strongly associated with the EBV in his pathogenesis [7]. EBV was the first human tumor virus described in 1970; the virus genome is identified in the atypical tumor cells of BL and other lymphoid neoplasm. In consequence, DNA sequences of this virus may be found in B cells and elevated titers of antiEBV antibodies are detected in patients with BL [8]. Treatment of BL is similar to other aggressive lymphomas; the Magrath regimen, used in the described patient, include the CODOX-M (cyclophosphamide, doxorubicin, vincristine with intrathecal methotrexate and cytarabine followed by high-dose of systemic methotrexate) e IVAC (ifosfamide, cytarabine, etoposide and intrathecal methotrexate) has been associated with a good clinical response $[9,10]$. The CODOX-M/IVAC regimen was developed by Magrath et al and showed a similar and excellent rate of response in adults with BL. CODOX-M/IVAC is a short regimen associated with high cure rates of nearly $90 \%$ [11].

The survival of patients with AIDS-related NHL is significantly longer compared with the preHAART era, with high rates of complete remission and prolonged response to HAART, as we can see in our patient $[12,13]$. Prolonged survival is significantly associated with achievement of a complete remission and a good virological response to HAART [14]. In comparison with a median survival of 7 months after NHL diagnosis in the pre-HAART era, the survival is prolonged in the post-HAART period $[12,13,15]$.

\section{CONClusion}

The association of HAART and chemotherapy is safety and effective, improving the clinical response rate and the prognosis of this kind of patients $[3,16]$.

\section{REFERENCES}

[1] Kaplan LD, Abrams DI, Feigal E, et al. AIDSassociated non-Hodgkin's lymphoma in San Francisco. JAMA 1989;261:719-24.

[2] Centers for Disease Control (CDC). Revision of the case definition of acquired immunodeficiency syndrome for national reporting United Sates. MMWR Morb Mortal Wkly Rep 1985;4:373-4.

[3] Vaccher E, Spina M, di Gennaro G, et al. Concomitant CHOP chemotherapy and highly active antiretroviral therapy in patients with HIV-related non-Hodgkin's lymphoma. Cancer 2001;91:155-63.

[4] Ratner L, Lee J, Tang S, et al. Chemotherapy for human immunodeficiency virus-associated non-Hodkin's lymphoma in combination with highly active antiretroviral therapy. J Clin Oncol 2001;91:2171-8.

[5] Beral V, Peterman T, Berkelman L, Jaffe H. AIDS-associated non_hodgkin's lymphoma. Lancet 1991;337:805-9.

[6] Masoodi I. Burkitt's lymphoma of stomach: Report of a case and literature review. Ann $\mathrm{Br}$ Med Sci 2018;4:3-6.

[7] Corti M. Burkitt's lymphoma associated with HIV Infection. Clin Microbiol 2016;5: 232-4.

[8] Almeida Freitas R, Vera Barros SS, Bezerra Quinderé L. Oral Burkitt's lymphoma-case report. Rev Bras Otorrinolaringol 2008;74: 458-61.

[9] Blinder VS, Chadburn A, Furman RR, Mathew $S$, Leonard JP. Improving outcomes for patients with Burkitt lymphoma and HIV. AIDS Patient Care STDs 2008;22:175-87.

[10] Wang ES, Strauss DJ, Teruya-Feldstein J, Qin $\mathrm{J}$, Portlock C, et al. Intensive chemotherapy with cyclofosfamide, doxorubicin, high-dose methotrexate/ifosfamide, etoposide, and highdose cytarabine (CODOXM/IVAC) for human immunodeficiency virus-associated Burkitt lymphoma. Cancer 2003;98:1196-1205.

[11] Perkins AS, Friedberg JW. Burkitt lymphoma in adults. Hematology Am Soc Hematol Educ Program Book 2008:341-348.

[12] Chow KU, Mitrou PS, Geduldig K, Helm EB, Hoelzer D, Brodt HR. Changing incidence and survival in patients with AIDS-related nonHodgkin's lymphoma in the era of highly active antiretroviral therapy (HAART). Leuk Lymphoma 2001;41:106-16. 
[13] Hoffmann C, Wolf E, Fatkenheuer G, Buhk T, Stoehr A, Plettenberg A, et al. Response to highly active antiretroviral therapy strongly predicts outcome in patients with AIDS-related lymphoma. AIDS 2003;17:1521-9.

[14] Wolf T, Brodt HR, Fichtlscherer S, Mantzsch K, Hoelzer D, Helm EB, et al. Leuk Lymphoma 2005;46:207-15.
[15] Straus DJ. HIV-associated lymphomas. Curr Opin Oncol 1997;9:450-4.

[16] Besson C, Goubar A, Gabarre J, et al. Changes in AIDS-related lymphoma since the era of highly active antiretroviral therapy. Blood 2991;98:2339-44.

Citation: Cárdenas G, Corti M, Campitelli A, Narbaitz M, Bistman A. Nodal Burkitt'S Lymphoma in an AIDS Patient under HAART with a Good Clinical, Immunological and Virological Response. ARC Journal of Clinical Case Reports. 2020; 6(1): 9-12. doi:dx.doi.org/ 10.20431/2455-9806.0601003.

Copyright: (C) 2020 Authors. This is an open-access article distributed under the terms of the Creative Commons Attribution License, which permits unrestricted use, distribution, and reproduction in any medium, provided the original author and source are credited. 